\title{
Protective effect of genistein aglycone on the development of osteonecrosis of the femoral head and secondary osteoporosis induced by methylprednisolone in rats
}

\author{
Alessandra Bitto, Francesca Polito, Bruce Burnett ${ }^{1}$, Robert Levy ${ }^{1}$, Vincenzo Di Stefano, \\ Mary Ann Armbruster ${ }^{1}$, Herbert Marini ${ }^{2}$, Letteria Minutoli, Domenica Altavilla \\ and Francesco Squadrito
}

Section of Pharmacology, Department of Clinical and Experimental Medicine and Pharmacology, Torre Biologica 5th Floor, c/o AOU Policlinico G. Martino, Via C. Valeria Gazzi, 98125 Messina, Italy

${ }^{1}$ Primus Pharmaceuticals, Inc., Scottsdale, Arizona 85251, USA

${ }^{2}$ Section of Physiology and Human Nutrition, Department of Biochemical, Nutritional and Physiological Sciences, University of Messina, 98125 Messina, Italy (Correspondence should be addressed to F Squadrito; Email: francesco.squadrito@unime.it)

\begin{abstract}
Glucocorticoid (GC)-induced osteoporosis (GIO) is the most important secondary cause of bone loss. Clinical evidence suggests a role for genistein (GEN) aglycone in the prevention of osteoporosis. We investigated whether GEN could prevent GIO as well as the development of osteonecrosis in the femoral head using an experimental rat model. A total of 28 female SpragueDawley rats were used in the study. GIO and osteonecrosis were induced by daily s.c. injections of $30 \mathrm{mg} / \mathrm{kg}$ of methylprednisolone (MP; $n=7$ ). Another group of animals (MP+GEN; $n=7)$ concomitantly received MP (30 mg $/ \mathrm{kg}$ per s.c.) and GEN aglycone $(5 \mathrm{mg} / \mathrm{kg}$ per i.p.) for 60 days. Control animals were administered daily with vehicle (VEH) or GEN ( $5 \mathrm{mg} / \mathrm{kg}$ per i.p.) only. At the beginning and end of the treatment, animals were examined for bone mineral density (BMD) and bone mineral content (BMC). After killing, serum was collected
\end{abstract}

to determine bone-alkaline phosphatase (b-ALP), carboxyterminal collagen crosslink (CTX) and osteoprotegerin (OPG) levels. Femurs were removed and tested for breaking strength and bone histology analyzed for structural quality of the femoral neck. GEN aglycone prevented bone loss as measured by BMD and BMC. Moreover, GEN significantly increased the bone formation markers b-ALP and OPG, reduced the bone resorption marker CTX and statistically maintained comparable strength versus the VEH only group. Finally, histological scoring revealed a protective effect of GEN on bone structure statistically comparable with the VEH control animals. Results suggest that the GEN aglycone might be a preventive treatment for GIO and complications of osteonecrosis with long-term GC treatment.

Journal of Endocrinology (2009) 201, 321-328

\section{Introduction}

The exact prevalence of glucocorticoid (GC)-induced osteoporosis (GIO) remains unclear. It is estimated, however, that in $30-50 \%$ of patients under chronic, long-term GC therapy, relevant bone loss occurs and 1 out of 4 also develop some degree of osteonecrosis (Mankin 1992, Cooper et al. 1995, Reid 1997, Lavernia et al. 1999). Intermittent use of GC only results in small increases in risk of fracture (de Vries et al. 2007). Still, a fracture caused by osteoporosis can lead to huge costs, especially in the case of hip fractures. By contrast, the prophylaxis of osteoporosis has a markedly lower cost and improves patient's quality of life (Kanis et al. 2007).

Bone loss induced by GCs occurs early and progresses at a fast rate becoming significant within the first 6 months (van Staa et al. 2002). GC therapy is responsible for bone loss via different mechanisms that can be summarized as a decrease in bone formation and an increase in bone resorption. More specifically, GCs affect bone metabolism directly by inhibiting osteoblasts from producing new bone and decreasing osteoblast proliferation, while increasing osteoclast activity (Reid 1997, McIlwain 2003). In addition, GCs have been shown to inhibit osteoprotegrin production that further damps osteoblast function (Canalis 2003). GCs also increase apoptosis of osteocytes, which are an independent determinant of bone strength different from bone mineral density (BMD), leading to micro-architectural deterioration (Spreafico et al. 2008). Induction of osteocyte apoptotic pathways have been implicated in osteonecrosis as well (Weinstein et al. 2000). Bekler et al. (2007) attributes osteonecrosis to non-vascular events that induce necrotic cell death in the femoral head. The triggers for this avascular event appear to be related to tumour necrosis factor- $\alpha$, RANK 
ligand, and osteoprotegerin (OPG) balance in GC-treated osteoblasts, which may also affect differentiation of osteoclasts thus triggering the apoptotic events (Bejar et al. 2005).

GCs have other systemic effects on bone metabolism and in particular on calcium homeostasis. In fact, there is a decreased absorption from the intestine and an increased loss of calcium in the urine as a result of defective vitamin $\mathrm{D}_{3}$ metabolism (Cosman et al. 1994, Patschan et al. 2001). Decreases in calcium and vitamin $\mathrm{D}_{3}$ homeostasis lead to secondary hyperparathyroidism, which, in turn, produces increased bone resorption (McIlwain 2003). Finally, GCs affect bone metabolism indirectly by reducing levels of sex hormones (Vestergaard 2008).

Two types of bone are present in the skeleton: cortical (also known as compact) bone found along the shafts of the long bones (femur, tibia, radius, and ulna) and the flat bones (skull and ribs), and trabecular (also known as cancellous) bone, which is considerably finer and more delicate in appearance. Trabecular bone is found principally in the vertebrae of the spinal column and at the epiphyses of the long bones. Trabecular bone is lost more rapidly than cortical bone reflecting a greater rate of bone turnover (Eriksen et al. 1994). As a consequence, the lumbar spine is the first site in which GIO can be detected. A significantly increased risk of non-vertebral fractures within the first 3 months of treatment has also been observed (van Staa et al. 2000).

A wide variety of pharmacological interventions have been shown to decrease bone loss in GIO as well as osteonecrosis of the femoral head. Proposed treatments include bisphosphonates, hormone replacement therapy, vitamin D (cholecalciferol or calciferol) and calcium, calcitriol, calcidiol, alfacalcidol, calcitonin, fluoride, testosterone, and anabolic steroids (Adachi et al. 1996, Ringe et al. 1999, Eastell et al. 2000, Boutsen et al. 2001, Astrand \& Aspenberg 2002, Crandall 2002, Sambrook 2007). In addition, several alternative therapeutic approaches have been considered in recent years.

Genistein (GEN) aglycone is an isoflavone found in low concentrations in soybeans and elevated amounts in certain soy-derived food, whereas genistin, the glucoside form of the aglycone GEN, is much more abundant in the unprocessed soybean (Messina et al. 2004). We previously showed that treatment with $>98 \%$ pure GEN aglycone $(54 \mathrm{mg} /$ day) increased BMD at the lumbar spine and femoral neck in osteopenic, postmenopausal women with no clinically significant adverse effects on the breast and uterus (Morabito et al. 2002, Crisafulli et al. 2004, Marini et al. 2007, 2008a,b). Furthermore, very recently it has been demonstrated that GEN at the same doses, adjusted for rat body weight and surface area, was more efficacious than alendronate or raloxifene or estradiol in treating primary osteoporosis induced by ovariectomy (Bitto et al. 2008) and secondary osteoporosis (Bitto et al. 2009). In light of these observations, this animal study presents results that suggest that GEN aglycone may be a new option for the preventive management of GIO-induced bone loss and osteonecrosis of the femoral head.

\section{Materials and Methods}

\section{Animals}

All procedures were evaluated and approved by the Ethics committee of the University of Messina and the study procedures complied with the standards for care and use of animal subjects as stated in the Guide for the Care and Use of Laboratory Animals (Institute of Laboratory Animal Resources, National Academy of Sciences, Bethesda, MD, USA). A total of 28, 8-month-old female Sprague-Dawley rats (Charles River, Calco, Italy) weighing 250-275 g were used in this study. During the experiment, animals were housed in the Animal Facility of the Department of Clinical and Experimental Medicine and Pharmacology, maintained under controlled environmental conditions (12 h light: $12 \mathrm{~h}$ darkness cycle, temperature $\sim 24^{\circ} \mathrm{C}$ ), and provided with access to standard food for laboratory animals and water ad libitum.

\section{Induction of osteoporosis, randomization, and treatments}

The study protocol is summarized in Fig. 1. Briefly, a group of animals $(n=7)$ was injected daily with methylprednisolone (MP; $30 \mathrm{mg} / \mathrm{kg}$, subcutaneously) and the dissolution vehicle (VEH; $10 \% \mathrm{DMSO} /$ in $0.9 \% \mathrm{NaCl}$ solution) of GEN aglycone (MP) for 60 days to produce $\mathrm{GIO}$ and osteonecrosis of the femoral head. Another group of animals (MP + GEN; $n=7)$ was dosed concomitantly with MP and GEN $(5 \mathrm{mg} / \mathrm{kg}$ per i.p.) each day. A third group of animals $(n=7)$ was administered with the MP VEH $(1 \mathrm{ml} / \mathrm{kg}$, subcutaneously of a $0.9 \% \mathrm{NaCl}$ solution) daily and served as controls (VEH only), and a last group received only GEN (5 mg/kg per i.p.; GEN $n=7)$. The treatment lasted 60 days.

\section{BMD and bone mineral content}

$\mathrm{BMD}$ and the relative bone mineral content (BMC) of the femurs were measured using dual-energy X-ray absorptiometry (Hologic QDR-4500A, Waltham, MA, USA). For basal and final measurements, animals were kept anesthetized with sodium pentobarbital $(50 \mathrm{mg} / \mathrm{kg}$ i.p.). During the analysis period, daily measurements were made for BMD and BMC following the manufacturer's instructions, in order to assess the long-term reproducibility of the measured parameters (QC). A measured value of $\pm 1 \cdot 5 \%$ was taken as acceptable. Whenever two points obtained in succession were found outside the limits of the QC curve, the procedure was repeated. The coefficient of variation for femur BMD and BMC was 1.15 and $1 \cdot 10 \%$ respectively. Moreover, accuracy of BMD and BMC final measurements were determined by duplicate scans of femurs.

\section{Biochemical analysis}

At the end of the study, animals were killed under general anesthesia with chloral hydrate $(400 \mathrm{mg} / \mathrm{kg}$ i.p.) after blood collection by cardiac puncture. Blood was centrifuged and 


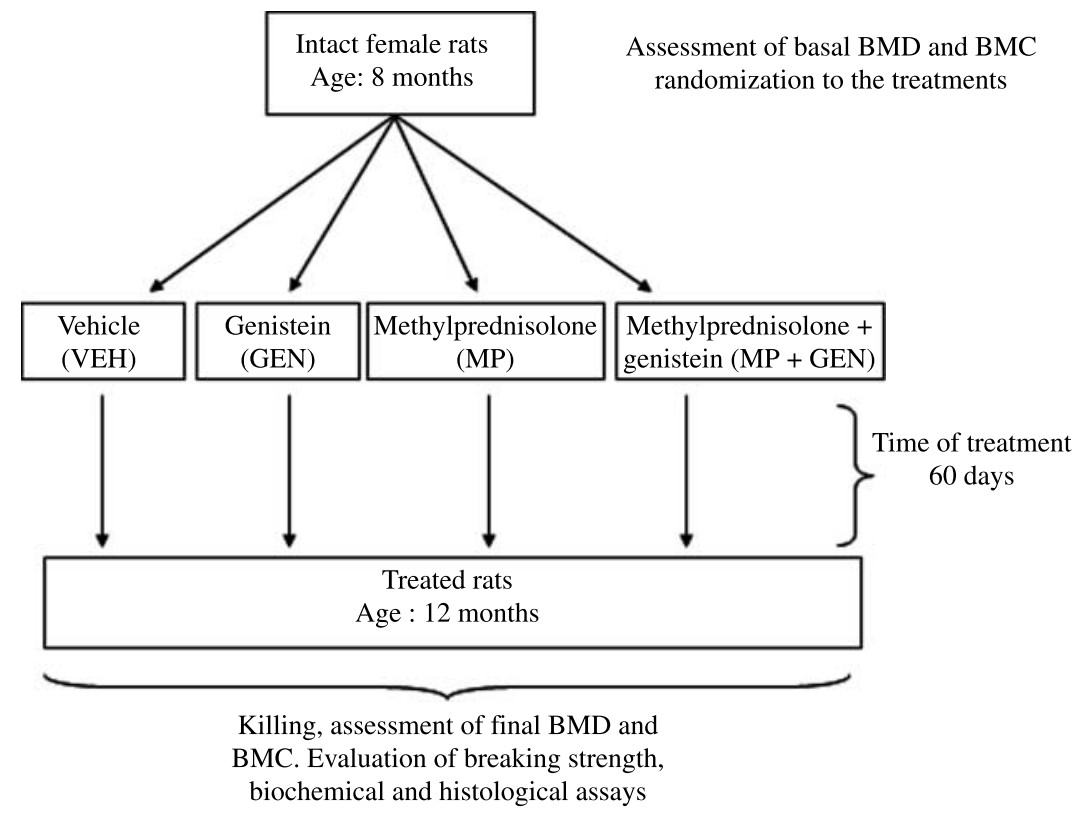

Figure 1 Flow chart of the experimental protocol.

serum stored immediately at $-20^{\circ} \mathrm{C}$ for analysis. Commercially available ELISA kits for b-ALP (IDS Plc), CTX (Nordic Bioscience Diagnostics, Beijing, China), and OPG (IDS Ltd) were then used to evaluate sera in duplicate for each animal for bone formation and resorption markers respectively.

\section{Histology}

Analysis was performed by an investigator blinded to the treatment groups. For tissue collection, the leg was disarticulated at the hip, knee, and ankle. For microscopic histological evaluation, femurs were removed and immediately fixed in 10\% neutral-buffered formalin. The femur was cleaned of soft tissue, placed in decalcifying solution $(8 \% \mathrm{HCl}$ from $37 \%(\mathrm{v} / \mathrm{v})$ concentrate and $10 \%$ formic acid from $89 \%$ (v/v) concentrate in PBS) for $\sim 24 \mathrm{~h}$ at $37^{\circ} \mathrm{C}$, dehydrated in graded ethanol, and then embedded in paraffin. Three 5 - $\mu$ m-thick paraffin-embedded horizontal bone sections were cut from the proximal end of the diaphysis, dyed with a haematoxylin-eosin stain and studied using light microscopy. Femoral heads (area comprised between hip joint cartilage and metaphyseal cartilage) were used to judge the quality of cartilage, bone, and trabecular density according to the scores reported in Table 1.

\section{Femur-breaking strength}

At the moment of killing, the maximum load (breaking strength) tolerated by femurs was measured on coded samples using a calibrated tensometer (Sans) assessed by an investigator blinded to the treatment groups. A three-point bending strength test was performed, femurs were placed horizontally on a two-point sample holder (15 $\mathrm{mm}$ span) with the anterior aspect facing up, and a load was placed at the center of the bone at a rate of $10.0 \mathrm{~mm} / \mathrm{min}$ until the bone fractured, maximum tolerated load was expressed in Newton $(\mathrm{N})$.

\section{Drugs}

GEN aglycone ( $>98 \%$ pure) was a kind gift of Primus Pharmaceuticals Inc., Scottsdale, AZ, USA. All substances were prepared fresh daily and administered in a volume of $100 \mu \mathrm{l}$. Route of administration was chosen according to

Table 1 Criteria for the evaluation of the histological score used to assess the degree of osteoporosis

\begin{tabular}{|c|c|c|c|}
\hline & Hip-joint cartilage integrity & Structure of trabecular bone & $\begin{array}{l}\text { Quantity of trabecular bone } \\
(\% \text { of interest area })\end{array}$ \\
\hline Score 0 & Cartilage complete & Normal & $90-100$ \\
\hline Score 1 & Cartilage complete & Partially reduced & $60-90$ \\
\hline Score 2 & Cartilage partially complete & Markedly reduced & $30-60$ \\
\hline Score 3 & Cartilage absent & Absent & $0-30$ \\
\hline
\end{tabular}


VEH. For $\mathrm{MP}$, we used only $0.9 \% \mathrm{NaCl}$, thus was administered subcutaneously. For GEN aglycone, we used DMSO. Thus, to avoid a poor absorption, we chose to administer it intraperitoneally.

\section{Statistical analysis}

All data are expressed as means \pm s.D. The significance of differences in BMD of the femoral neck and BMC was assessed by a two-way repeated-measures ANOVA followed by Tukey's multiple comparison test. For all other data, comparisons between different treatments were analyzed by one-way ANOVA followed by Tukey's multiple comparison test. In all cases, a probability error of $<0.05$ was selected as the criterion for statistical significance. Graphs were drawn using GraphPad Prism (version 4.0 for Windows).

\section{Results}

\section{Effect on femoral BMD and BMC}

Following MP administration over a period of 60 days, animals had a significant decrease in BMD at the femoral neck $\left(0 \cdot 240 \pm 0 \cdot 003 \mathrm{~g} / \mathrm{cm}^{2}\right)$ compared with VEH only treated animals $\left(0.269 \pm 0.002 \mathrm{~g} / \mathrm{cm}^{2} ; P<0 \cdot 001\right)$, and in BMC $(0 \cdot 416 \pm 0 \cdot 004$ versus $\mathrm{VEH}$ only $(0 \cdot 431 \pm 0 \cdot 001 \mathrm{~g}$; $P<0 \cdot 001)$. At the end of the treatment period, GEN was found not only to maintain BMD (Fig. 2A) and BMC (Fig. 2B) in GC-treated animals, but also significantly increased BMD $\left(0 \cdot 267 \pm 0 \cdot 001 \mathrm{~g} / \mathrm{cm}^{2} ; \quad P<0 \cdot 001\right.$ versus $\mathrm{MP})$ and $\mathrm{BMC}(0.432 \pm 0.001 \mathrm{~g} ; \quad P<0.001$ versus $\mathrm{MP})$
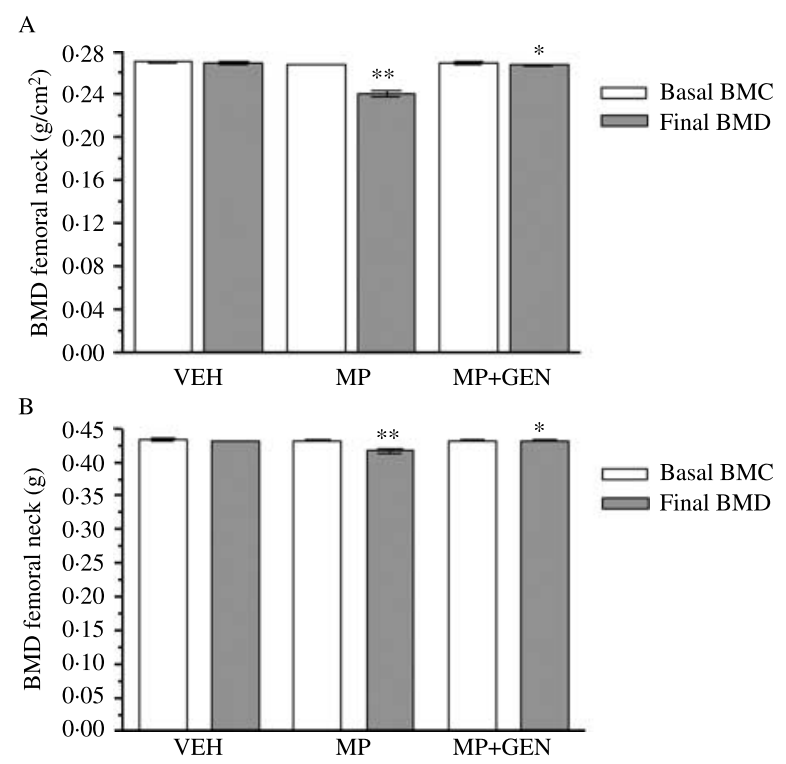

Figure 2 Effects of aglycone genistein on femoral bone mineral density (BMD) and bone mineral content (BMC) in methylprednisolone-treated rats. Data are shown as the mean \pm s.D. of seven animals. ${ }^{*} P<0 \cdot 01$ versus Sham MP; ${ }^{* *} P<0 \cdot 005$ versus MP+VEH. compared with the MP group. GEN alone did not significantly improve $\mathrm{BMD}$ and $\mathrm{BMC}$ in naive animals (data not shown).

\section{Effect on bone markers}

At the end of the experiment, serum b-ALP levels were higher (Fig. 3A) in the MP group than in the VEH only group $(P<0 \cdot 001)$. GEN increased the bone formation marker b-ALP even further in MP animals $(135 \cdot 42 \pm 2 \cdot 99 ; P<0 \cdot 005$ versus $\mathrm{MP})$ as well as in naive animals $(130 \pm 4 ; P<0.001$ versus $\mathrm{VEH})$, confirming the positive role of the pure isoflavone in stimulating osteoblast activity (Fig. 3A). Another bone formation marker, OPG (Fig. 3B), was increased in serum from animals in the GEN and $\mathrm{MP}+\mathrm{GEN}$ groups $(P=0 \cdot 018$ versus $\mathrm{VEH}$ and $P<0 \cdot 001$ versus $\mathrm{MP})$. MP alone caused a marked decrease in OPG $(P<0 \cdot 001$ versus VEH). In addition, plasma levels of the bone resorption marker CTX were significantly higher in the MP group than in the $\mathrm{VEH}$ only group $(P<0 \cdot 005)$ at the end of the experiment (Fig. 3C). The concomitant treatment of MP animals with GEN significantly reduced CTX plasma levels $(78.78 \pm 2.09 \mathrm{ng} / \mathrm{ml} ; P<0.001$ versus $\mathrm{MP})$ compared with VEH only animals, but especially compared with the MP group (Fig. 3C).

\section{Effect on the mechanical properties of the femur and on bone} histology

Results obtained from the three-point bending test of the femur showed that the MP+VEH group had a significant reduction in breaking strength compared with $\mathrm{VEH}$ only rats $(P<0.001$; Fig. 3D). The concomitant administration of GEN, however, succeeded in preserving the breaking strength of the femur compared with the VEH only animals $(P<0 \cdot 001$; Fig. 3D). GEN alone only slightly improved bone strength in untreated animals when compared with VEH group.

Histological scores were evaluated at the end of the experiment on femoral heads, according to the criteria shown in Table 1. GC treatment significantly reduced cortical bone, deteriorated bone micro-architecture, and eroded the hip-joint cartilage shown in the MP group. There was also evidence, as shown in the histology, that the femoral heads had undergone osteonecrosis similar to that seen in other work with high MP administration (Bekler et al. 2007). GEN, however, prevented osteonecrosis, bone erosion and maintained a normal bone architecture comparable with the VEH group (Fig. 3E). Femoral heads collected from GEN-treated rats in the presence of MP (Fig. 4D) showed a normal shape with intact cartilage, qualitatively equivalent cortical bone, well-organized bone matrix composed of trabecular bone comparable with the VEH only (Fig. 4A), and prevented the damage shown in the MP group (Fig. 4C). GEN alone as expected stimulated bone remodeling in naive animals (Fig. 4B). 
A

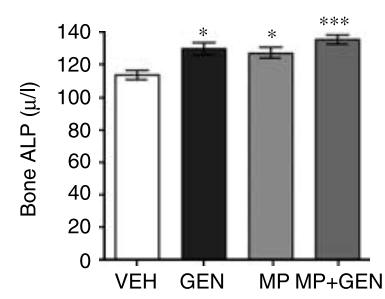

B

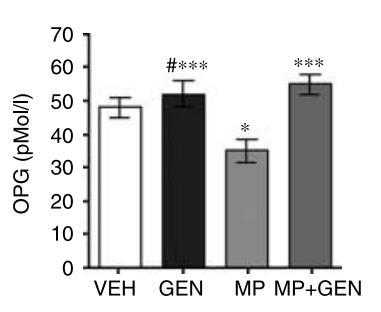

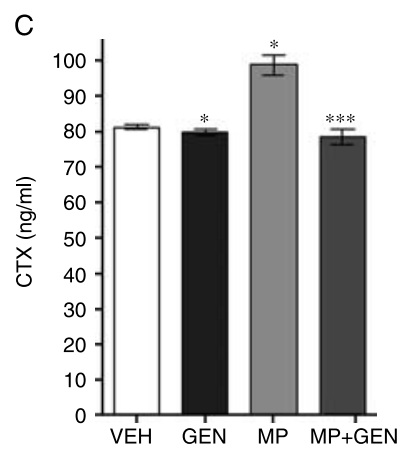

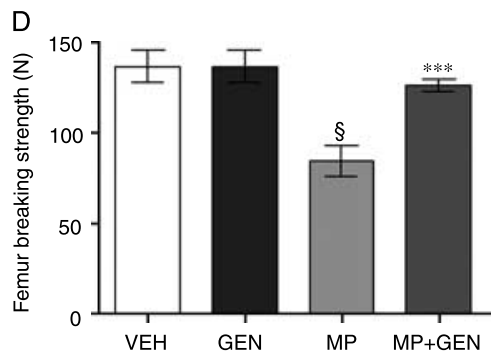

E

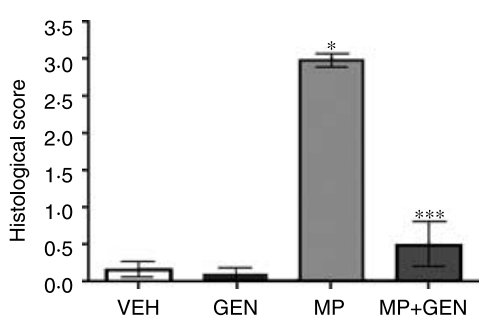

Figure 3 Effects of aglycone genistein on serum bone-alkaline phosphatase (b-ALP), osteoprotegerin (OPG), collagen C-telopeptides (CTX), femur-breaking strength, and histological score in methylprednisolone-treated rats. Data are shown as the mean \pm s.D. of seven animals. b-ALP, ${ }^{*} P<0.001$ versus $\mathrm{VEH} ;{ }^{* * *} P<0 \cdot 005$ versus MP. OPG, ${ }^{*} P=0.018$ versus $\mathrm{VEH} ;{ }^{*} P<0 \cdot 001$ versus VEH; ${ }^{* * *} P<0 \cdot 001$ versus MP. CTX, $* P<0 \cdot 005$ versus VEH; ${ }^{* * *} P<0 \cdot 001$ versus MP. Femurbreaking strength, ${ }^{\S} P<0 \cdot 001$ versus $V E H$; ${ }^{* * *} P<0 \cdot 001$ versus MP. Histological score, ${ }^{*} P<0 \cdot 001$ versus VEH; $* * * P<0 \cdot 001$ versus MP.

\section{Discussion}

Several studies and reports show a decrease in BMD and an increased risk of fractures during GC use as well as an increase in osteonecrosis with chronic steroid use. Approximately $30 \%$ of all fractures of the hip and almost half of all fractures of the spine can be attributed to chronic, high-dose GC use in humans (van Staa et al. 2001). Prior and current exposure to GCs increases the risk of fractures beyond that explained by values of BMD (Civitelli \& Ziambaras 2008). The main effect of GCs on bone is inhibition of osteoblastogenesis, augmented continued osteoclastogenesis and osteocyte apoptosis, leading to a decrease in bone formation, a rapid weakening of bone architecture and an increase in fracture risk (Manolagas \& Weinstein 1999). Chronic administration of steroids also causes avascular necrosis via an apoptotic mechanism of osteocytes and osteoblasts (Weinstein et al. 2000, Bekler et al. 2007). Once osteonecrosis occurs, GC administration appears to also inhibit bone regeneration (Takano-Murakami et al. 2009).

Pharmacological intervention for prevention of GCinduced osteoporosis is needed depending on dose, expected duration of treatment, age and gender of the patient, and sometimes BMD at the start of the GC therapy. At present, calcium and vitamin $\mathrm{D}_{3}$ supplementation are considered as important support for the prevention of GC-induced osteoporosis (Williams et al. 2004). Bisphosphonates are largely used to avoid bone loss and are cost effective in certain subgroups of patients depending on age, gender, GC dose, and previous fracture history (Williams et al. 2004, Prinsloo \& Hosking 2006). Unfortunately, calcium and vitamin $\mathrm{D}_{3}$ supplementation may not be enough to stave off bone deterioration and bisphosphonates have safety risks associated with long-term use, such as esophageal burns and bone and muscular pain (Ettinger et al. 1998, Wysowski \& Chang 2005). Osteonecrosis of the jaw, although rare and found primarily in cancer patients undergoing dental surgery, is a very serious and debilitating side effect of bisphosphonate use (Durie et al. 2005). Therefore, a safe and effective treatment for the prevention of bone loss and osteonecrosis of the femoral head in GC-treated subjects is still needed. Recent clinical and experimental evidence suggests a role for the isoflavone GEN aglycone in the treatment of primary bone loss and osteoporosis (Morabito et al. 2002, Crisafulli et al. 2004, Marini et al. 2007, 2008a,b, Bitto et al. 2008).

Based on earlier studies, we used MP to produce bone loss as well as osteonecrosis of the femoral head (Sevitt 1964, Bejar et al. 2005, Bekler et al. 2007) in the rat and we studied GEN aglycone preservative effects. One drawback of this model is its GC effect on cartilaginous structures (Peskin et al. 2001). 


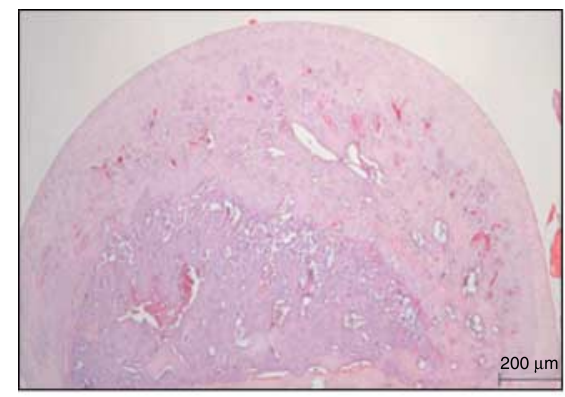

VEH

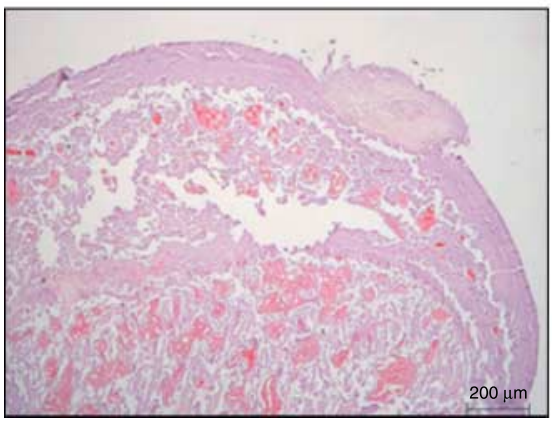

MP

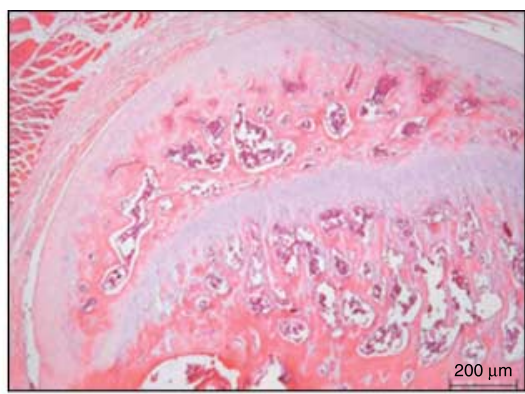

GEN

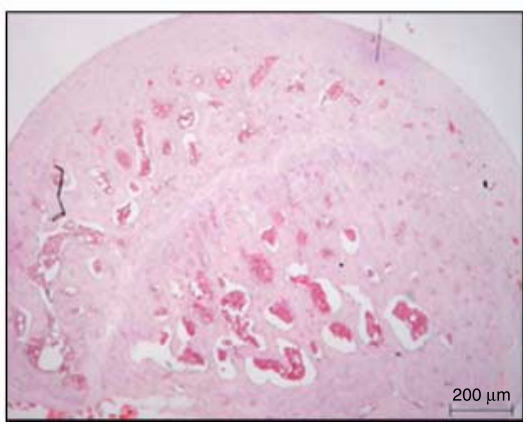

$\mathrm{MP}+\mathrm{GEN}$

Figure 4 Light microscopy of the bone structure of the femur head. (H\&E original magnification $\times 5$ ).

In our study, GEN succeeded in preventing GC-induced osteoporosis and osteonecrosis of the femoral head when co-administered with MP. This purified isoflavone statistically maintained BMD and BMC over the MP-treated group and showed comparable efficacy with the VEH only group. GEN co-administered with MP also statistically maintained femoral bone's resistance to rupture compared with the MP group and prevented the histological damage seen in the MP group. GEN alone or co-administered with MP caused a significant increase in b-ALP over MP and VEH only confirming its role as a bone-forming agent. MP administration caused an increase in bone remodeling as reflected by increased B-ALP and CTX levels in MP animals. In the MP+GEN group, there was a significant reduction in CTX compared with the MP group suggesting an anti-resorptive effect. There was also a small decrease in CTX levels in the VEH only group suggesting a suppressive effect of GEN on bone resorption in this rat model. The diverse mechanism of action for GEN aglycone's effect on bone metabolism is still not well understood.

GC therapy has been shown to cause apoptosis in osteoblasts and inhibit the production of osteoprotegrin required for bone formation, while RANK-L accumulates resulting in further bone resorption (Bejar et al. 2005). GEN has been shown to stimulate the production of osteoblasts via inhibition of a RANK-L-resorptive mechanism by producing osteoprotegrin (Viereck et al. 2002). This was also confirmed in the present paper where
GEN increased OPG levels in either naive or MP-treated animals. OPG is a glycoprotein secreted by osteoblasts in a differentiation-dependent manner and acts as a 'decoy receptor' (a soluble receptor that acts as antagonist) for RANK-L regulating osteoclast functions and lifespan. GEN aglycone, in human clinical trials, increases BMD and also promotes bone formation through the stimulation of the OPG/sRANK-L system in postmenopausal women with bone loss, as well as in osteoporotic rats (Morabito et al. 2002, Crisafulli et al. 2004, Marini et al. 2007, $2008 a, b)$, the same phenomenon shown in osteoporotic rat models (Bitto et al. 2008).

GEN was shown in neonatal rats to decrease GC receptor levels in the liver (Csaba \& Inczefi-Gonda 2002). Using a reporter gene assay system in Chinese hamster ovary cells, various flavonoids, including GEN aglycone, were not found to be agonists on the GC receptor (Takeuchi et al. 2009). Similarly, liquiritigenin, a closely related structural polyphenol and a strong agonist of the estrogen receptor- $\beta$ $($ ER- $\beta$ ) like GEN, did not activate GC receptors in transfection assays (Mersereau et al. 2008). Conversely, a strong GC such as dexamethasone appears not to interact with ER complexes (Wilson et al. 2004). Rather, GEN may act on the molecular level to inhibit transcription of GC receptors or cause their degradation. Moreover, Wallace \& Cidlowski (2001) found that a proteosome-ubiquitin pathway regulates the production of GC receptors. It appears that GEN inhibits GC receptor transactivation and may also induce 
a proteosomal degradation of the GC receptor complex via the p53 and ubiquitin pathways (Kinyamu \& Archer 2003). Finally, GEN's tyrosine kinase inhibitor activity may play a role by limiting the subcellular nuclear transport and recycling of the GC receptors thereby inhibiting the effects of GC on bone (Yang et al. 1997).

It has been reported that GEN acts on de novo protein synthesis and on amplification of the interaction between the ER complex and nuclear DNA in osteoblasts. These cells express both ER- $\beta$ and ER- $\alpha$ at low levels until stimulated. GEN appears to act on trabecular bone by a mechanism involving ER- $\beta$ upregulation during bone mineralization phase (Kuiper et al. 1998). The dose that we chose to administer was the same (human equivalent) dose of GEN aglycone used in our previous clinical trials (Morabito et al. 2002, Crisafulli et al. 2004, Marini et al. 2007, 2008a,b).

The positive effects of GEN on prevention of GC-induced osteoporosis and osteonecrosis in the present experimental model are confirmed by the enhanced femoral breaking strength together with the preserved bone morphology observed in GEN-treated animals in the presence of MP. Normal architecture of cartilage as well as both cortical and trabecular bones with a well-organized matrix in femoral head of MP + GEN-treated rats was observed. This finding significantly correlates with the enhanced resistance to fracture observed in femurs subjected to a constant load. Furthermore, GEN alone in naive animals stimulated bone remodeling as confirmed by the biochemical markers, mechanical tests, and histology.

Collectively, our results strongly suggest that GEN aglycone might be a new potential therapy for the prevention of GC-induced osteoporosis, the most important secondary cause of osteoporosis in humans. And in the minority of cases, GEN may prevent necrotic deterioration of the femoral head. Usually, drugs used in management of osteoporosis have been classified as predominantly 'antiresorptive agents' or as 'bone-forming agents', but, on the basis of the present results, GEN aglycone might represent the first therapy to overcome this classification combining a powerful bone-forming as well as an anti-resorptive activity.

\section{Declaration of interest}

Bruce Burnett, Robert Levy, and Mary Ann Armbruster currently work for Primus Pharmaceuticals, Inc., Scottsdale, Arizona, USA. Primus only provided us genistein aglycone. Dr Burnett, Levy, and Armbruster were involved in the design of the experiment. Dr Burnett also helped us in critical revision of the manuscript. All the other authors have nothing to declare.

\section{Funding}

This work has been performed with Departmental funding only.

\section{References}

Adachi JD, Bensen WG, Bianchi F, Cividino A, Pillersdorf S, Sebaldt RJ, Tugwell P, Gordon M, Steele M, Webber C et al. 1996 Vitamin D and calcium in the prevention of corticosteroid induced osteoporosis: a 3 year follow up. Journal of Rheumatology 23 995-1000.

Åstrand J \& Aspenberg P 2002 Systemic alendronate prevents resorption of necrotic bone during revascularization. A bone chamber study in rats. $B M C$ Musculoskeletal Disorders 719.

Bejar J, Peled E \& Boss JH 2005 Vasculature deprivation - induced osteonecrosis of the rat femoral head as a model for therapeutic trials. Theoretical Biology and Medical Modelling 224.

Bekler H, Uygur AM, Gökçe A \& Beyzadeoğlu T 2007 The effect of steroid use on the pathogenesis of avascular necrosis of the femoral head: an animal model. Acta Orthopaedica et Traumatologica Turcica 41 58-63.

Bitto A, Burnett BP, Polito F, Marini H, Levy RM, Armbruster MA, Minutoli L, Di Stefano V, Irrera N, Antoci S et al. 2008 Effects of genistein aglycone in osteoporotic, ovariectomized rats: a comparison with alendronate, raloxifene and oestradiol. British Journal of Pharmacology 8 1-10.

Bitto A, Burnett B, Polito F, Levy R, Marini H, Stefano VD, Irrera N, Armbruster M, Minutoli L \& Altavilla D et al. 2009 Genistein aglycone reverses glucocorticoid-induced osteoporosis and increases bone breaking strength in rats: a comparative study with alendronate. British Journal of Pharmacology 156 1287-1295.

Boutsen Y, Jamart J, Esselinckx W \& Devogelaer JP 2001 Primary prevention of glucocorticoid-induced osteoporosis with intravenous pamidronate and calcium: a prospective controlled 1 -year study comparing a single infusion, an infusion given once every 3 months, and calcium alone. Journal of Bone and Mineral Research 16 104-112.

Canalis E 2003 Mechanisms of glucocorticoid-induced osteoporosis. Current Opinion in Rheumatology 15 454-457.

Civitelli R \& Ziambaras K 2008 Epidemiology of glucocorticoid-induced osteoporosis. Journal of Endocrinological Investigation 31 2-6.

Cooper C, Coupland C \& Mitchell M 1995 Rheumatoid arthritis, corticosteroid therapy and hip fracture. Annals of the Rheumatic Diseases $\mathbf{5 4}$ $49-52$

Cosman F, Nieves J, Herbert J, Shen V \& Lindsay R 1994 High-dose glucocorticoids in multiple sclerosis patients exert direct effects on the kidney and skeleton. Journal of Bone and Mineral Research 9 1097-1105.

Crandall C 2002 Parathyroid hormone for treatment of osteoporosis. Archives of Internal Medicine 162 2297-2309.

Crisafulli A, Altavilla D, Squadrito G, Romeo A, Adamo EB, Marini R, Inferrera MA, Marini H, Bitto A, D'Anna R et al. 2004 Effects of the phytoestrogen genistein on the circulating soluble receptor activator of nuclear factor kappaB ligand-osteoprotegerin system in early postmenopausal women. Journal of Clinical Endocrinology and Metabolism 89 188-192.

Csaba G \& Inczefi-Gonda A 2002 Effect of a single treatment (imprinting) with genistein or combined treatment with genistein + benzpyrene on the binding capacity of glucocorticoid and estrogen receptors of adult rats. Human and Experimental Toxicology 21 231-234.

Durie BG, Katz M \& Crowley J 2005 Osteonecrosis of the jaw and bisphosphonates. New England Journal of Medicine 353 99-102.

Eastell R, Devogelaer JP, Peel NF, Chines AA, Bax DE, Sacco-Gibson N, Nagant de Deuxchaisnes C \& Russell RG 2000 Prevention of bone loss with risedronate in glucocorticoid-treated rheumatoid arthritis patients. Osteoporosis International 11 331-337.

Eriksen E, Axelrod D \& Melsen F 1994 Bone Histomorphometry. New York: Raven Press.

Ettinger B, Pressman A \& Schein J 1998 Clinic visits and hospital admissions for care of acid-related upper gastrointestinal disorders in women using alendronate for osteoporosis. American Journal of Managed Care $\mathbf{4}$ 1377-1382.

Kanis JA, Stevenson M, McCloskey EV, Davis S \& Lloyd-Jones M 2007 Glucocorticoid-induced osteoporosis: a systematic review and cost-utility analysis. Health Technology Assessment 11 1-231. 
Kinyamu HK \& Archer TK 2003 Estrogen receptor-dependent proteasomal degradation of the glucocorticoid receptor is coupled to an increase in Mdm2 protein expression. Molecular and Cellular Biology 23 5867-5881.

Kuiper GG, Lemmen JG, Carlsson B, Corton JC, Safe SH, van der Saag PT, van der Burg B \& Gustafsson JA 1998 Interaction of estrogenic chemicals and phytoestrogens with estrogen receptor beta. Endocrinology 139 4252-4263.

Lavernia CJ, Sierra RJ \& Grieco FR 1999 Osteonecrosis of the femoral head. Journal of the American Academy of Orthopaedic Surgeons 7 250-261.

Mankin HF 1992 Nontraumatic necrosis of bone (osteonecrosis). New England Journal of Medicine 326 1473-1479.

Manolagas SC \& Weinstein RS 1999 New developments in the pathogenesis and treatment of steroid-induced osteoporosis. Journal of Bone and Mineral Research 14 1061-1066.

Marini H, Minutoli L, Polito F, Bitto A, Altavilla D, Atteritano M, Gaudio A, Mazzaferro S, Frisina A, Frisina N et al. 2007 Effects of the phytoestrogen genistein on bone metabolism in osteopenic postmenopausal women: a randomized trial. Annals of Internal Medicine 146 839-847.

Marini H, Bitto A, Altavilla D, Burnett BP, Polito F, Di Stefano V, Minutoli L, Atteritano M, Levy RM, D'Anna R et al. 2008a Breast safety and efficacy of genistein aglycone for post-menopausal bone loss: a follow-up study. Journal of Clinical Endocrinology and Metabolism 93 4787-4796.

Marini H, Minutoli L, Polito F, Bitto A, Altavilla D, Atteritano M, Gaudio A, Mazzaferro S, Frisina A, Frisina N et al. 2008b OPG and sRANKL serum concentrations in osteopenic, postmenopausal women after 2-year genistein administration. Journal of Bone and Mineral Research 23 715-720.

McIlwain HH 2003 Glucocorticoid-induced osteoporosis: pathogenesis, diagnosis, and management. Preventive Medicine 36 243-249.

Mersereau JE, Levy N, Staub RE, Baggett S, Zogric T, Chow S, Ricke WA, Tagliaferri M, Cohen I, Bjeldanes LF et al. 2008 Liquiritigenin is a plantderived highly selective estrogen receptor $\beta$ agonist. Molecular and Cellular Endocrinology 283 49-57.

Messina M, Ho S \& Alekel DL 2004 Skeletal benefits of soy isoflavones: a review of the clinical trial and epidemiologic data. Current Opinion in Clinical Nutrition and Metabolic Care 7 649-658.

Morabito N, Crisafulli A, Vergara C, Gaudio A, Lasco A, Frisina N, D’Anna R, Corrado F, Pizzoleo MA, Cincotta M et al. 2002 Effects of genistein and hormone-replacement therapy on bone loss in early postmenopausal women: a randomized double-blind placebo-controlled study. Journal of Bone and Mineral Research 17 1904-1912.

Patschan D, Loddenkemper K \& Buttgereit F 2001 Molecular mechanisms of glucocorticoid-induced osteoporosis. Bone 29 498-505.

Peskin B, Shupak A, Levin D, Zinman C, Norman D, Misselevich I, Reis DN \& Boss JH 2001 Chondrolysis in rats with vascular deprivation induced osteonecrosis of the femoral head. European Journal of Orthopedic Surgery and Traumatology 11 15-20.

Prinsloo PJJ \& Hosking DJ 2006 Alendronate sodium in the management of osteoporosis. Journal of Therapeutics and Clinical Risk Management 2 235-249.

Reid IR 1997 Glucocorticoid osteoporosis - mechanisms and management. European Journal of Endocrinology 137 209-217.

Ringe JD, Coster A, Meng T, Schacht E \& Umbach R 1999 Treatment of glucocorticoid-induced osteoporosis with alfacalcidol/calcium versus vitamin D/calcium. Calcified Tissue International 65 337-340.

Sambrook PN 2007 Anabolic therapy in glucocorticoid-induced osteoporosis. New England Journal of Medicine 357 2084-2086.

Sevitt S 1964 Avascular necrosis and revascularisation of the femoral head after intracapsular fractures. A combined arteriographic and histological necropsy study. Journal of Bone and Joint Surgery. British Volume 46 270-296.
Spreafico A, Frediani B, Francucci CM, Capperucci C, Chellini F \& Galeazzi M 2008 Role of apoptosis in osteoporosis induced by glucocorticoids. Journal of Endocrinological Investigation 31 22-27.

van Staa TP, Leufkens HG, Abenhaim L, Zhang B \& Cooper C 2000 Use of oral corticosteroids and risk of fractures. Journal of Bone and Mineral Research 15 993-1000.

van Staa TP, Abenhaim L, Cooper C, Zhang B \& Leufkens HGM 2001 Public health impact of adverse bone effects of oral corticosteroids. British Journal of Clinical Pharmacology 51 601-607.

van Staa TP, Leufkens HG \& Cooper C 2002 The epidemiology of corticosteroid-induced osteoporosis: a meta-analysis. Osteoporosis International 13 777-787.

Takano-Murakami R, Tokunaga K, Kondo N, Ito T, Kitahara H, Ito M \& Endo N 2009 Glucocorticoid inhibits bone regeneration after osteonecrosis of the femoral head in aged female rats. Tohoku Journal of Experimental Medicine 217 51-58.

Takeuchi S, Takahashi T, Sawada Y, Iida M, Matsuda T \& Kojima H 2009 Comparative study on the nuclear hormone receptor activity of various phytochemicals and their metabolies by reporter gene assays using Chinese hamster ovary cells. Biological and Pharmaceutical Bulletin 32 195-202.

Vestergaard P 2008 Skeletal effects of systemic and topical corticosteroids. Current Drug Safety 3 190-193.

Viereck V, Gründker C, Blaschke S, Siggelkow H, Emons G \& Hofbauer LC 2002 Phytoestrogen genistein stimulates the production of osteoprotegrin by human trabecular osteoblasts. Journal of Cellular Biochemistry $\mathbf{8 4}$ 725-735.

de Vries F, Bracke M, Leufkens HGM, Lammers JWJ, Cooper C \& van Staa TP 2007 Fracture risk with intermittent high-dose oral glucocorticoid therapy. Arthritis and Rheumatism 56 208-214.

Wallace AD \& Cidlowski JA 2001 Proteasome-mediated glucorticoid receptor degradation restricts transcriptional signaling by glucocorticoids. Journal of Biological Chemistry 276 42714-42721.

Weinstein RS, Nicholas RW \& Manolagas SC 2000 Apoptosis of osteocytes in glucocorticoid-induced osteonecrosis of the hip. Journal of Clinical Endocrinology and Metabolism 85 2907-2912.

Williams D, Bennett K \& Feely J 2004 Prescribing for osteoporosis following the use of inhaled and oral glucocorticoids in general practice. British Journal of Clinical Pharmacology 58 665-672.

Wilson VS, Bobseine K \& Gray LE Jr 2004 Development and characterization of a cell line that stably expresses an estrogen-responsive luciferase reporter for the detection of estrogen receptor agonist and antagonists. Toxicological Sciences 81 69-77.

Wysowski DK \& Chang JT 2005 Alendronate and risedronate: reports of severe bone, joint, and muscle pain. Archives of Internal Medicine $\mathbf{1 6 5}$ 346-347.

Yang J, Liu J \& DeFranco DB 1997 Subnuclear trafficking of glucocorticoid receptors in vitro: chromatin recycling and nuclear export. Journal of Cell Biology 137 523-538.

Received in final form 24 March 2009

Accepted 30 March 2009

Made available online as an Accepted Preprint 30 March 2009 